\title{
aniki
}

Revista Portuguesa da Imagem em Movimento

Portuguese Journal of the Moving Image

\section{Sobre Descasco as Imagens e Entrego-as na Boca: Lições António Reis}

\author{
Ana Isabel Soares
}

Universidade do Algarve e Centro de Investigação em Artes e Comunicação asoares@ualg.pt

https://orcid.org/o0oo-0003-2324-8319

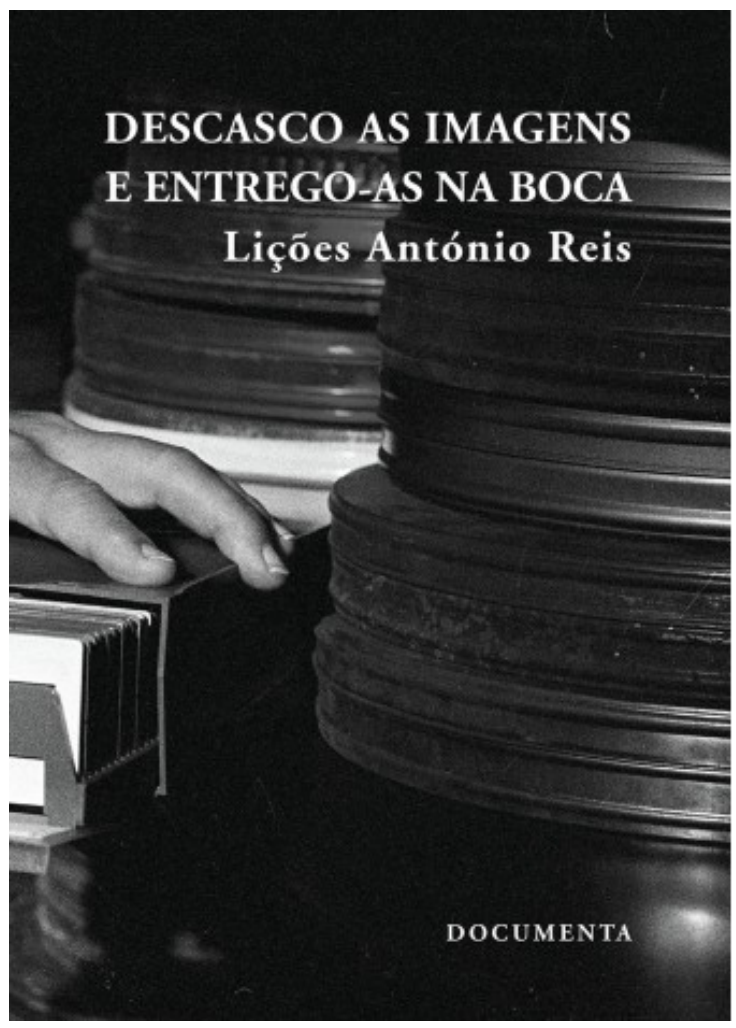

Bogalheiro, José e Guerra, Manuel (ed.). 2020. Descasco as Imagens e Entrego-as na Boca: Lições António Reis. Lisboa: Documenta. 207 pp. ISBN 978-989-9006-05-8.

Na capa de Descasco as Imagens e Entrego-as na Boca: Lições António Reis, reproduz-se uma fotografia de Maria Patrão incluída no ensaio desta, que compõe a terceira parte do livro, "Continuação" (pp. 185201): a mão de António Reis sobre uma carreta de slides, ao lado de caixas de bobines de película fílmica. A mão sai de uma manga de 
couro, do casaco que Reis (1927-1991) enverga em algumas das fotos que se lhe conhecem. Está a mão do homem, estão os materiais das suas aulas - o professor - e está a matéria do seu cinema - o cineasta. Esta é a tríade de que se fez o poeta (não necessariamente na cronológica sequência, mas é como, depois de tudo, ela é vista), e terá sido ele a presidir à homenagem que o livro de que aqui falo lhe consagra (que um professor que não seja poeta não bastará como professor, assim como um cineasta abaixo de poeta não terá quanto baste de cineasta). O título assinala essa presidência, versos retirados do poema "22" de Poemas Quotidianos que Reis fez publicar em 1957, antes de assinar em nome próprio o seu primeiro filme, Jaime (1974): "descasco as imagens / e entrego-as na boca // como quem sabe / o corpo / mais importante / que a roupa" (2017: 40). O poeta é, pois, orago.

Porque a poesia, antes e dentro do cinema e do magistério, é uma arte do tempo - e porque José Bogalheiro invocou, em 1997, a deleuziana "reversibilidade espaço/tempo" como categoria repetida nas aulas de António Reis (Moutinho e Lobo 1997: 57) -, esta coleção de quatro das Lições António Reis (revistos e aumentados os textos dessas aulas, que Maria Filomena Molder, Nuno Júdice, Manuel Guerra e José Bogalheiro apresentaram, em outubro de 2018, na Escola Superior de Teatro e Cinema, na Amadora), somadas a uma homenagem de Fátima Ribeiro e ao testemunho da pesquisa de uma disciplina de licenciatura de Maria Patrão, é organizada por duas pessoas que assinalam um marcante arco temporal da existência de António Reis.

José Bogalheiro, à altura das Lições, diretor da Escola Superior de Teatro e Cinema, representava os alunos no Conselho Diretivo da Escola quando acompanhou Reis, em 1977, na sua entrada no então Conservatório Nacional. No depoimento que dele dá na monografia $A$ Poesia da Terra, afirma ter-se desde logo apercebido do "radical antiacademismo" do mestre - mas essa posição, percebe-se pelas palavras de Bogalheiro, então como agora, seria mais um anti-institucionalismo, um recusar da "normalização narrativa", jamais um afastar-se do modo da mais antiga academia que toma como central o diálogo entre mestres e discípulos, entre gerações e modos temporais de agir dentro da intemporalidade poética. É o que justifica que Bogalheiro, como é seu feliz apanágio, sustente o discurso do ensaio que neste volume inclui nas três referências, fundamentos ou justificativas, digo eu, que conduziram à estruturação das Lições: a Poética aristotélica 
(consensualmente um guia de magistério), o Curso de Linguística Geral de Ferdinand de Saussure (fixado e organizado por alunos do linguista a partir, precisamente, das suas aulas) e duas obras de Ludwig Wittgenstein - resultado de apontamentos, notas dirigidas aos alunos, esquiços para usufruto de um bom debate filosófico (que quem o saber ama conhece ser da ordem do poético, do inventivo). Ou que sistemática e academicamente (no melhor sentido do termo) convoque mais mestres do pensamento da pedagogia e da aprendizagem (além de Deleuze, Focillon, Foucault, João dos Santos - sobre Jaime - e, nada surpreendentemente, a poesia de Luiza Neto Jorge). As digressões de Bogalheiro em volta de, a partir de e de regresso a António Reis (passando por um belíssimo exercício de "close-reading" dos versos de Reis e por um confronto dialogante entre as palavras deste e as de um dos seus mais assumidos mestres, Robert Bresson) tornam o poeta, cineasta e professor, à vez, centro e margem do fluxo das ideias: como deve ser, no gesto de o devolver ao presente para jamais ressurgir o "indevido silêncio". Por outras palavras, remeter o mestre a um lugar de patrono não faz deter os que com ele vêm aprender, mas antes, libertando-os da cegueira da luz que dele emana, abre espaço a que se afirme e adense essa estrada iluminada.

O outro extremo do arco é Manuel Guerra, nascido no ano da morte de António Reis. Antigo aluno da Escola de Cinema, estudante, portanto, de discípulos de Reis, veio a seguir - sem surpresa, mas imagina-se que com espanto - a via filosófica (numa pós-graduação em Filosofia, com especialização de Estética, da FCSH da Universidade Nova de Lisboa), e tem-se dedicado sobretudo à investigação em torno do primeiro filme de António Reis. O seu depoimento atravessa e ultrapassa Jaime, mas persiste na sua nomeação - é Ângelo, um anjo que se segue a Jaime Fernandes na "Atenção ardente" (expressão tomada de empréstimo a Herberto Helder) que Guerra dedica a estas figuras num "reverso da reflexão" - um movimento de descasque que traz às páginas do livro as capas de obras de Reis: as edições dos seus poemas, desde Chamas (1947) até à que, vinte anos depois, a Portugália publicou a coligir Poemas Quotidianos, alguns dos Novos Poemas Quotidianos, além de transcrições de poemas. A direção do anjo conduz até Santo Agostinho e à sua proposta de entendimento sobre o que seja o Tempo: o foco numa inessencialidade do presente faz entender as muitas formas de poesia de Reis, inscrito num fio luminoso que vai da água (de Ângelo pescador, passando por fotografias das artes e do que foi pescado) ao céu esvaziado no ponto onde se fixa a lua. 
Dentro do arco traçado por Guerra e por Bogalheiro, acoita-se a ousada e branda prosa de Maria Filomena Molder "sobre Jaime": a recusar, tal como Reis, um academismo formulaico, deixa emergir as palavras da atenção, o conforto do coloquialismo ("Lembrei-me logo", "Ai o que se perdeu com isso!”, p. 41) que faz do discurso a dádiva de um sussurro segregado. Fica o leitor a saber, por exemplo, da visita de Molder à $8 .^{a}$ Enfermaria do Miguel Bombarda (lugar dos "inimputáveis perigosos" e hoje mítica localização do cinema português), do seu olhar ao pormenor das sombras e do telheiro, depois pelo interposto olhar de Reis. É dela o diagnóstico fino da necessidade e da concretização da homenagem que é este livro, que foram as Lições, e a atribuição do nome de António Reis à sala nobre da Escola Superior de Teatro e Cinema: na transmissão de alunos de então para alunos de hoje, para alunos do futuro é onde "se faz justiça e se põem em prática as leis do coração" (p. 26). É também de Molder a leitura precisa de versos e de imagens que leva a perceber a importância da distinção entre palavras "aladas" e palavras "gravadas", as aulas perdidas e irrecuperáveis de Reis e o registo em livro do que consiga ficar - também ao texto de Molder assomam os anjos (na sua fala há sempre anjos a assomar), trazidos por alguns dos mestres das imagens que eram para Reis fulgores de ensinamento: Paul Klee, Miguel Ângelo, o olhar "penetrante" de Jaime. Além de tantos outros versos, tantos outros poemas, tantas outras idades. Talvez este ensaio de abertura seja peça fundamental para entrar em Reis: por um lado, porque se esquiva à Escola e ao âmbito institucional do cinema (tal como Nuno Júdice, de modo mais ligeiro); por outro lado, porque, na sintaxe molderiana, se vinca docemente a mesma candura do olhar de Reis e o mesmo fardo, carregado e repousado sobre quem ouve ou quem lê, das vozes ao longo do tempo. É este fardo que faz Filomena Molder ver como Reis "encontra uma relação profunda entre a obra de Jaime e a experiência barroca” (p. 50), quando associa à ideia de moldura (dos papeis que Jaime Fernandes enchia de tinta de esferográfica) a de clausura e limitação; que a faz ligar Jaime, Reis, Hokusai e Paulo Rocha; ou a leva a suspeitar a funda afinidade da poesia de Reis com o poético olhar de Palla e Costa Martins no livro-álbum fotográfico Lisboa "cidade triste e alegre" (2009: 56). De Reis transparece o mesmo amor que Molder à obra dele dedica.

Se o tempo deliu as formas, é o tempo que as pode resgatar, e nós nele: o legado dos filmes (aprisionados ainda na indisponibilização mais alargada) vai sendo, lentamente, trabalhado - com a preservação e 
digitalização das películas, pela Cinemateca Portuguesa-Museu do Cinema; o legado da poesia, com mais ou menos teimosia de rigor, vaise perpetuando, na reedição e nas leituras sucessivas (tão variadas como as de Rosa Maria Martelo e as de Cidalia Barbosa Pinto). Depois de, em 1997, o Cineclube de Faro ter denunciado a urgência deste resgate e atalhado itinerários de volta a António Reis, o legado do seu magistério aguardava ainda este marco de caminho a indicar um futuro, onde se juntam colegas, alunos (que são hoje professores, como Fátima Ribeiro, que lhe traça o perfil), alunos de alunos (como Maria Patrão e Francisco Borges, que fotografaram slides que Reis preparava para as aulas), e se amplia o percurso de um iluminado peregrino.

\section{Referências}

Moutinho, Anabela e Lobo, Maria da Graça (ed.). 1997. António Reis e Margarida Cordeiro: A Poesia da Terra. Faro: Cineclube de Faro.

Palla, Victor e Costa Martins, Manuel. 2009. Lisboa "cidade triste e alegre”. Lisboa: Pierre von Kleist Editions.

Reis, António. 2017 [1957]. Poemas Quotidianos. Lisboa: Tinta da China. 